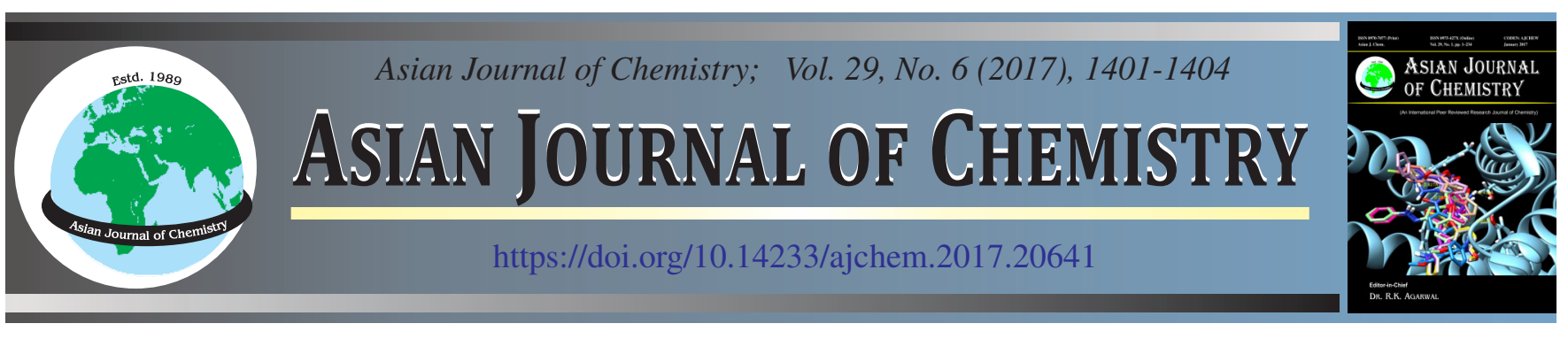

\title{
Creatinine Biosensor Based on Graphite Paste Electrode Modified with Dibenzo-30-crown-10 and Rice Husk
}

\author{
K.S. Paithankar ${ }^{1}$, V.B. Deshmukh ${ }^{1}$, U.N. Shelke ${ }^{1}$, S.B. Iyyer ${ }^{1}$, S.T. More ${ }^{2}$ and V.K. Gade ${ }^{3, *}$
}

\author{
${ }^{1}$ Department of Physics, Ahmednagar College, Ahmednagar-414 001, India \\ ${ }^{2}$ A.C.S. College, Jalna, India \\ ${ }^{3}$ Department of Physics, Shri Anand College, Pathardi-414 102, India \\ *Corresponding author: E-mail: paithankar86@gmail.com
}

Received: 3 March 2017;

Accepted: 31 March 2017;

Published online: 10 April 2017;

AJC-18361

\begin{abstract}
A novel electrochemical creatinine biosensor based on graphite paste electrode modified with dibenzo-30-crown-10 (DB30C10) and rice husk $(\mathrm{RH})$ has been developed for selective and quantitative recognition of creatinine by immobilizing enzyme creatinase for monitoring the amperometric response. Creatinase immobilization on electrode was investigated using amperometric method and factors affecting its immobilization such as potential as well as $\mathrm{pH}$ was discussed. The performance of the developed creatinine biosensor was evaluated and the obtained creatinine biosensor exhibited shorter response time $(3 \mathrm{~s})$, wider range $0.1-30 \mu \mathrm{M}$ and the detection limit were found to be $1 \times 10^{-7} \mathrm{M}$. About $90 \%$ of the enzyme activity is retained for about 60 days.

Keywords: Electrochemical, Biosensor, Immobilization.
\end{abstract}

\section{INTRODUCTION}

In the earlier decade, there is an expanding interest for basic, specific, exact and predictable investigation of the fundamental human metabolites that can be utilized for control of wellbeing position. Creatinine is one of such metabolites and its clinical test is huge for the determination of renal, thyroid and muscle dysfunctions and is essentially noteworthy in treatment with outside blood dialysis. For ordinary patients, the serum/plasma grouping of creatinine is 35-140 AM [1] and it can increment to higher than $1000 \mathrm{AM}$ at a few pathology [2]. Presently, in clinical research facilities, creatinine focus is most widely broke down by utilizing financially open analyzers in light of spectrophotometric identification of Jaffe' [3] response. This response is not extremely exact the same number of substances can meddle [4]. This is the reason the exact discovery of creatinine focus in the natural specimens remains an issue.

In present work, the electrochemical sensors in light of impartial sensors are well routine for some cation and chiral ammonium particles $[5,6]$. These reviews elevate us to attempt dibenzo-30-crown-10 (DB30C10) as an unbiased bearer sensor for creatinine. Rice husk $(\mathrm{RH})$ is favoured because of its minimal effort, simple openness or more each of the decent adsorbing property for creatinine [7]. Rice husk is the strong securing covers of grains of rice. Notwithstanding ensuring rice amid the developing season, rice husk can be put to use as adsorbents, building material, manure, protection material, or fuel. Utilizing the property of rice husk for the adsorption of creatinine, there is an awesome potential for it to be utilized as a modifier in the graphite glue cathode (GPE) for investigation of creatinine. It was collected in a traditional one compartment three anode framework plan, the working terminal was altered glue anode comprise of piece of 65:25:5:5 graphite:mineral oil:DB30C10:rice husk this glue allowable to homogenize for $1 \mathrm{~h}$. The glue was then filled in a plastic syringe. A platinum wire was dismembered inside the glue, to give an electrical contact. Smooth and crisp cathode surface were obtained by squeezing out $0.5 \mathrm{~mm}$ of glue from the syringe, scratching off the excess and cleaning it by margarine paper until the surface has a gleaming look and DB30C10/ $\mathrm{RH}$ composite in which the creatinase immobilized; the $\mathrm{Ag}$ / $\mathrm{AgCl}$ utilized as the reference terminal and a graphite use as the counter electrode.

\section{EXPERIMENTAL}

Method of treating rice husk: Rice husk was dried in daylight and polluting influences were isolated physically. It was overflowed with refined water up to $2 \mathrm{~h}$ to make it free from hued mixes. It was then separated. The leftover material so acquired was dried at $80^{\circ} \mathrm{C}$ in hot air broiler for $24 \mathrm{~h}$. Rice 
husk hence treated was ground till fine particles to the size 1-10 $\mathrm{m}$ are acquired. This powdered rice husk was utilized as a modifier in the graphite glue cathode. It is to be noted here that the creation of rice husk fluctuate starting with one vegetable kind then onto the next or notwithstanding relying upon the time at which gather process is completed. It is normal that its adsorptive conduct for creatinine would not change definitely.

Synthesis of enzyme based biosensor graphite/creatinase/DB30C10/RH (working electrode): The mixture of 65:25:5:5 graphite: mineral oil:DB30C10:rice husk allowed to homogenize for $60 \mathrm{~min}$. The glue was then filled in a plastic syringe micropipette tip. A platinum wire was dismembered through the glue, to offer an electrical contact. Delicate and crisp anode surfaces were acquired by pressing out $0.5 \mathrm{~mm}$ of glue from the tip, scratching off the over abundance and cleaning it against margarine paper.

Creatinase immobilization on the composite surface did by dropping of the PBS ( $\mathrm{pH} 7$ ) containing the compound on the cathode surface, which additionally dried at a controlled temperature. The working anode was set up by dropping 7.0 $\mu \mathrm{L}$ of refined creatinase arrangement onto the surface of the graphite/creatinase/DB30C10/RH cathode and hatching it at $20{ }^{\circ} \mathrm{C}$ for $24 \mathrm{~h}$. The terminal was flushed with refined water, dried and put away at $4{ }^{\circ} \mathrm{C}$ preceding use. This constitutes a genuine commitment from the composite surface to the proficiency of the biosensor without the cross-connecting specialists to make clinging to the dynamic locales of catalysts, along these lines restraining their action. The shapeless material clung to the DB30C10 is related to the creatinase.

\section{RESULTS AND DISCUSSION}

FTIR study: The FT-IR range of Gr/DB30C10/RH appears in Fig. 1 crest at $1400-600 \mathrm{~cm}^{-1}$ compares to C-C and $\mathrm{C}-\mathrm{O}$ holding. Additional confirmation of the nearness of this anion in the polymer terminal is uncovered by crests at 1500 1000 and $1800-1600 \mathrm{~cm}^{-1}$ which might be allotted to $\mathrm{C}=\mathrm{C}$ extend. The vibration groups are seen at $1784-1728 \mathrm{~cm}^{-1}(\mathrm{C}=\mathrm{O})$. Top at $770-750 \mathrm{~cm}^{-1}$ demonstrates ortho disubtituted sweetsmelling ring of DB30C10.

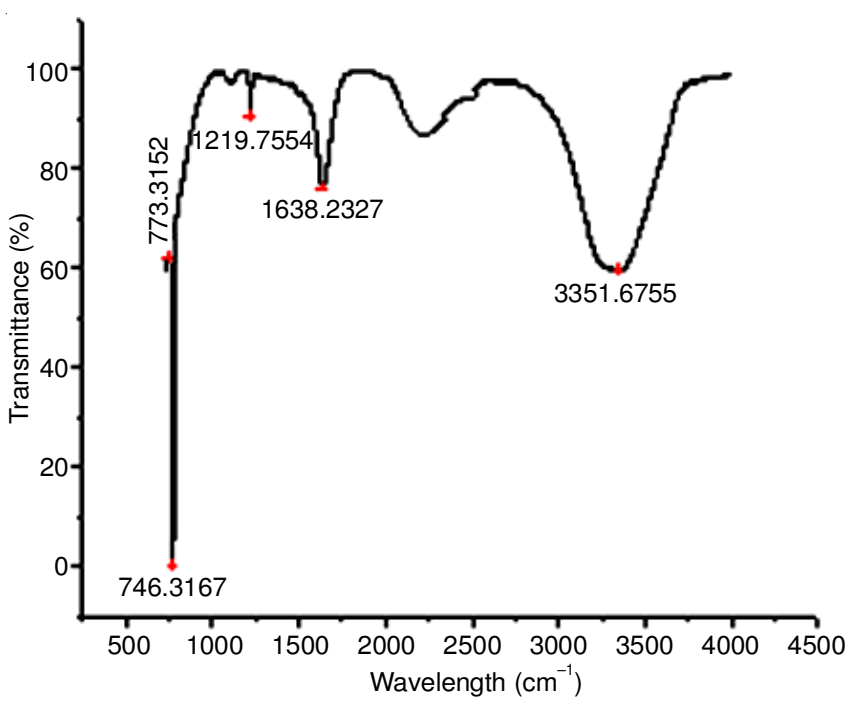

Fig. 1. FT-IR study of Gr/DB30C10/RH biosensor
SEM study: Fig. 2 looks at the morphological components of (a) Gr/DB30C10, (b)Gr/DB30C10/RH anodes utilizing SEM [Fig. 2(a)]. The SEM picture of Gr/DB30C10 is more uniform in nature and no isolated graphite particles could be watched, which shows the magnificent adherence of DB30C10 to graphite [Fig. 2(b)]. The SEM picture of $\mathrm{Gr} /$ DB30C10/RH indicates round about rice husk particles alongside the graphite particles. The rice husk can be seen at crystalline particles sharp edges of rice husk are obviously watched. Thus, it is normal that rice husk will add to the adsorption of analyte and DB30C10 will frame a composite with it. This synergistic impact will prompt to a superior execution of Gr/DB30C10/RH when contrasted with Gr/DB30C10.

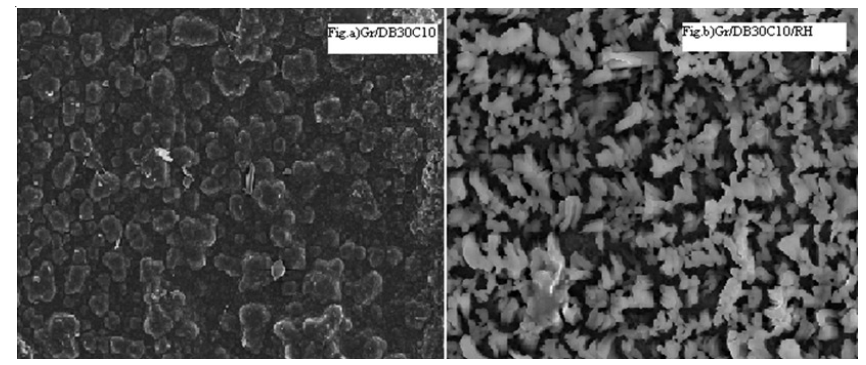

Fig. 2. SEM analysis of (a) Gr/DB30C10, (b) Gr/DB30C10/RH

Influence of $\mathbf{p H}$ and potential: The $\mathrm{pH}$ study was completed by changing the $\mathrm{pH}$ in the scope of 1 to 10 . The $\mathrm{pH}$ of the test arrangement was balanced utilizing $\mathrm{H}_{2} \mathrm{SO}_{4}$ and $\mathrm{NaOH}$. It likewise stays away from the loss of the chemical action. Thusly compound sensor reaction relies on upon the working $\mathrm{pH}$ of the inspecting arrangement. The impact of $\mathrm{pH}$ on the conduct of catalyst cathode was studied with $0.1 \mathrm{M}$ phosphate cushion arrangement with $5 \mathrm{mM}$ creatinine. The unfaltering state streams at $0.9 \mathrm{~V}$ as a component of $\mathrm{pH}$ qualities is appeared in Fig. 3(a) the electrochemical reaction is very great at $\mathrm{pH}$ extending from 5 to 8 and the most extreme current happened at $\mathrm{pH} 7$.

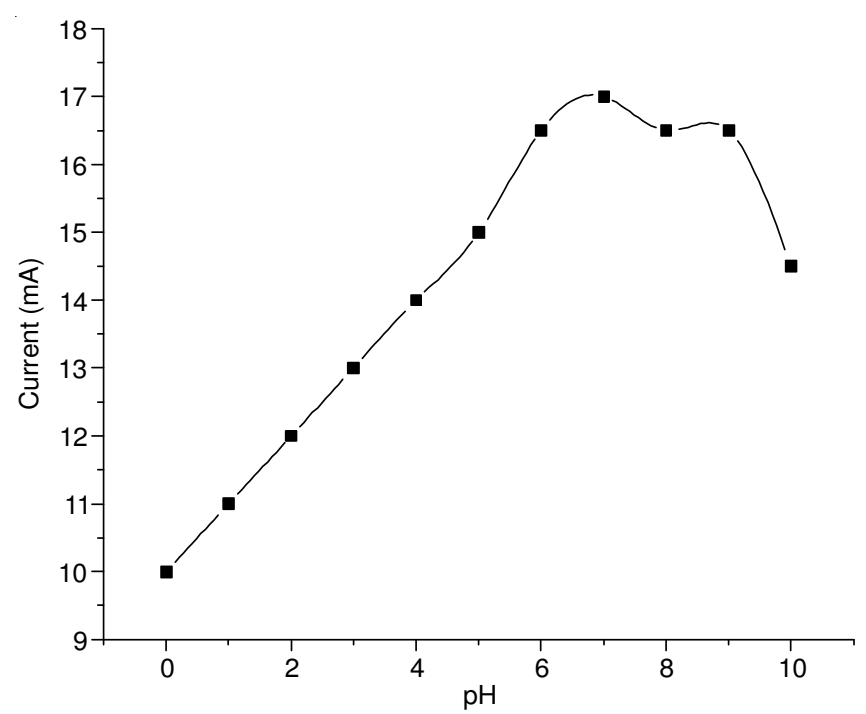

Fig. 3(a) Effect of $\mathrm{pH}$ on $\mathrm{Gr} / \mathrm{DB} 30 \mathrm{C} 10 / \mathrm{RH}$ at potential $0.9 \mathrm{~V}$

The reaction current increments rapidly with increment in potential, which indicates that the reaction of the terminal 
was controlled by the electrochemical strategies as appeared in Fig. 3(b). It is outstanding that the speed of a terminal reaction is related to the grouping of electroactive sort, the $\mathrm{pH}$ estimation of arrangement and apply potential. Over the potential $0.7 \mathrm{~V}$, the reaction was consistent, which could be clarified by the rate-restricting procedure of catalyst energy, dissemination control of $\mathrm{H}_{2} \mathrm{O}_{2}$ and substrate. Considering the reduction accordingly of the $\mathrm{Gr} / \mathrm{DB} 30 \mathrm{C} 10 / \mathrm{RH}$ terminal at higher potential, which likewise has influenced the electrochemical reaction of the compound anode, to set the potential at $0.9 \mathrm{~V}$ for the further investigations of $\mathrm{Gr} / \mathrm{DB} 30 \mathrm{C} 10 / \mathrm{RH}$ electrode.

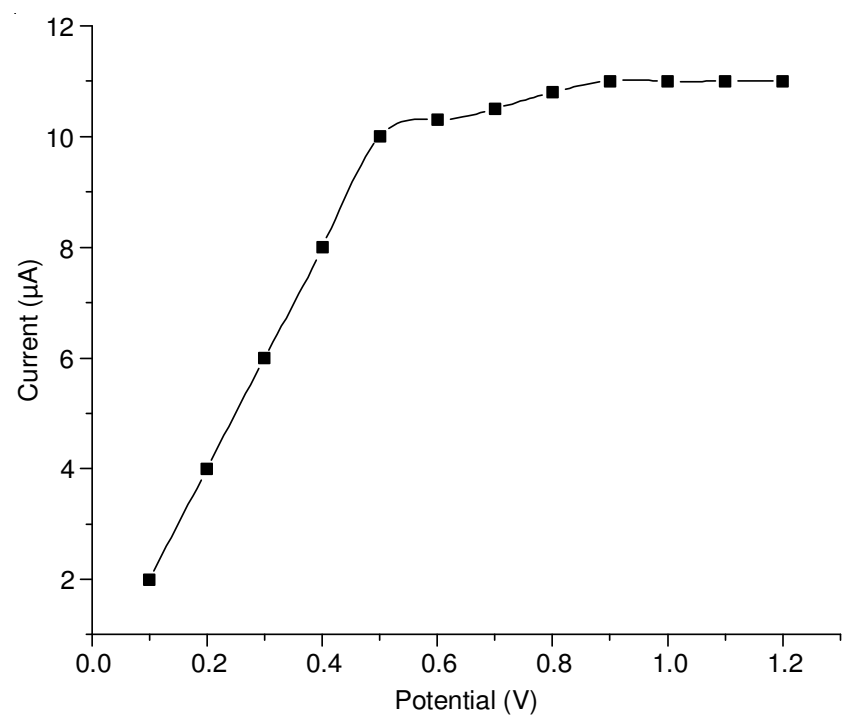

Fig. 3(b). Current-potential curve for Gr/DB30C10/RH

\section{Current-time reaction of Gr/DB30C10/RH electrode:}

The current-time relationship when the capability of the compound cathode was set at $0.9 \mathrm{~V}$ is as appeared in Fig. 4(a). It was found that the reaction current of the chemical terminal effectively reaches to consistent state. The connection between reaction current and creatinine focus in $0.1 \mathrm{M}$ phosphate support at $\mathrm{pH} 7$, it was found that the present increments with expanding creatinine fixation in the range $1 \times 10^{-7}$ to $9 \times 10^{-7}$ M. In the present case, expecting that the chemical is consistently conveyed all through the cathode, the response happens dominatingly on the surface of the terminal in the lower fixation. Be that as it may, the response on the surface of the terminal and the dispersion occurring at the same time at higher focuses defers the reaction time. With expanding centralizations of creatinine, the reaction current likewise expanded lastly came to enduring state esteem.

Fig. 4(b) demonstrates the unfaltering state potential reliance alignment bend for the every individual creatinine fixation in the scope of 0.1 to $40 \mu \mathrm{M}$. The reaction of $\mathrm{Gr} / \mathrm{DB} 30 \mathrm{C} 10 / \mathrm{RH}$ to creatinine was observed to be wide straight scope of 0.1-30 $\mu \mathrm{M}$ and as far as possible was observed to be $1 \times 10^{-7} \mu \mathrm{M}$. Linearity range is well concurrence with that got in the amperometric reaction of sensor is proper in extent to creatinine fixation.

Effect of incubation time and storage stability: Creatinine was tried regarding their impact on creatinase action at different brooding circumstances (0-20 min) in an analyte

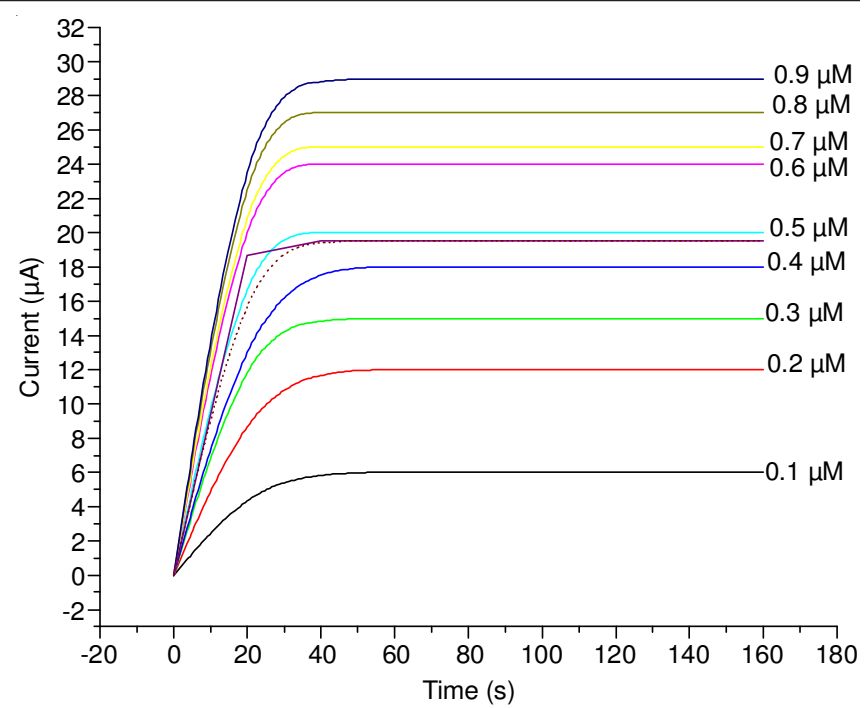

Fig. 4(a). Amperometric response of $\mathrm{Gr} / \mathrm{DB} 30 \mathrm{C} 10 / \mathrm{RH}$

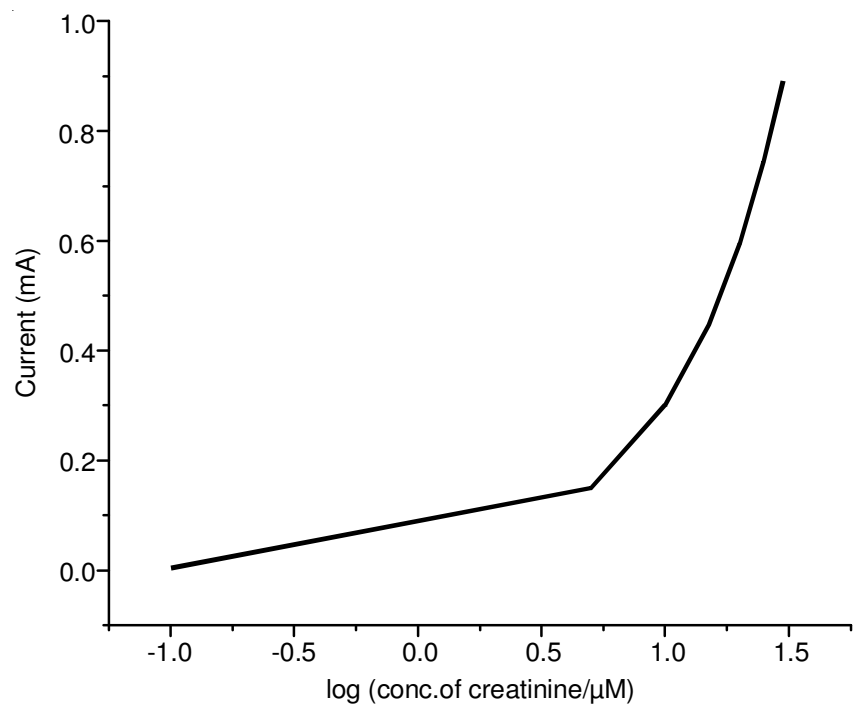

Fig. 4(b). Steady-state potential dependence calibration curve of biosensor Gr/DB30C10/RH

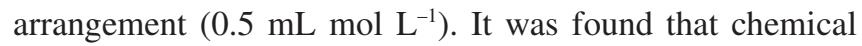
restraint expanded with hatching period length until achieving a level [Fig. 5(a)]. However, the abatement in action was less articulated after $7 \mathrm{~min}$. For all pesticides in this manner, a 7 min hatching time, which is greatly improved than before cathodes $[8,9]$. Long time security is a standout amongst the most critical components required for the tasteful utilization of a biosensor as appeared in Fig. 5(b). With a specific end goal to appraise the capacity strength, the sensor was tried for two months of capacity in $0.1 \mathrm{M}$ phosphate cushion $\mathrm{pH} 7$ at $25^{\circ} \mathrm{C}$. There is a slight diminishing in affectability of the sensor of around $12 \%$ from the underlying worth, uncovering a decent conservation of the bioactivity than other work [10]. Table-1 indicates correlation of various location techniques for creatinine utilizing distinctive nanocomposite material on enzymatic sensor.

\section{Conclusion}

A creatinine biosensor in light of Gr/DB30C10/RH has been effectively created. The soundness of the biosensor was enhanced by utilizing graphite and rice husk and to immobilize 
TABLE-1

COMPARISON OF DIFFERENT DETECTION METHOD FOR CREATININE

USING DIFFERENT NANOCOMPOSITE MATERIAL ON ENZYMATIC SENSOR

\begin{tabular}{|c|c|c|c|c|c|}
\hline Electrode fabrication & Method & Linear dynamic range & Limit of detection & $\mathrm{pH}$ & Ref. \\
\hline Poly(p-ABA-DCM) polymer film & $\mathrm{CV}$ & $1-35 \mathrm{ng} \mathrm{m} / \mathrm{L}$ & $0.11 \mathrm{ng} \mathrm{m} / \mathrm{L}$ & 7.1 & [11] \\
\hline Bienzymatic electrode & Potentiometric & $0.1-30 \mathrm{mM}$ & $10^{-5} \mathrm{M}$ & - & [13] \\
\hline Naflon poly (DAB) bilayer & Electroanalyzer & $1-100 \mu \mathrm{M}$ & - & 7.5 & [12] \\
\hline Hydrogel matrix & Amperometric & $1-150 \mu \mathrm{M}$ & $0.3 \mu \mathrm{M}$ & 7.5 & [14] \\
\hline Micro fabricated biosensor & Amperometric & $0-2 \mathrm{mM}$ & $20 \mu \mathrm{M}$ & 8 & [15] \\
\hline Gr/DB30C10 with rice husk & Amperometric & $0.1-30 \mu \mathrm{M}$ & $1 \times 10^{-7} \mathrm{M}$ & 7 & This work \\
\hline
\end{tabular}

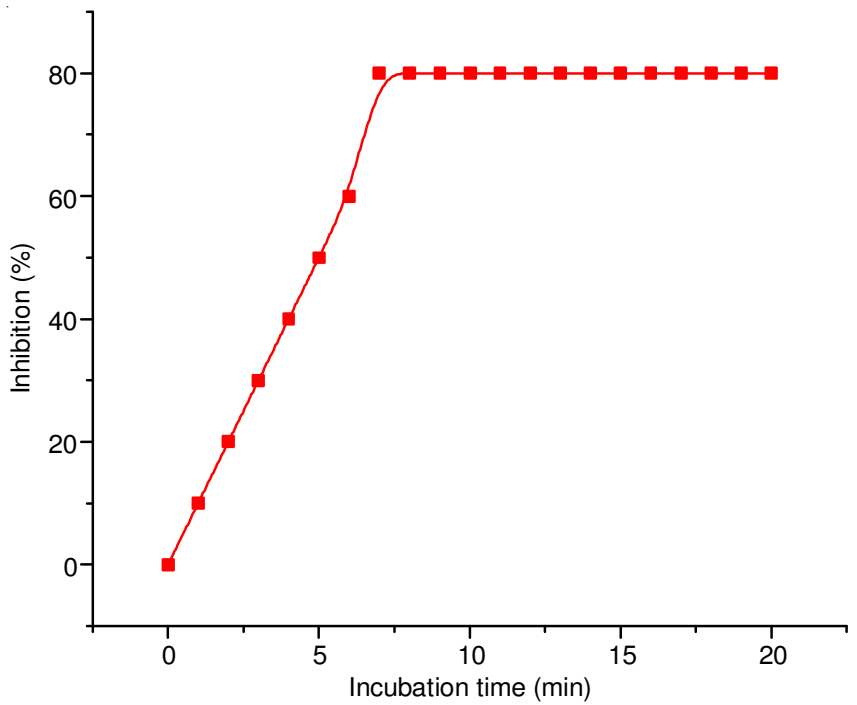

Fig. 5(a). Effect of inhibition time on creatinine $\left(0.5 \mathrm{mmol} \mathrm{L}^{-1}\right.$ concentration) at $0.9 \mathrm{~V} v s . \mathrm{Ag} / \mathrm{AgCl}$

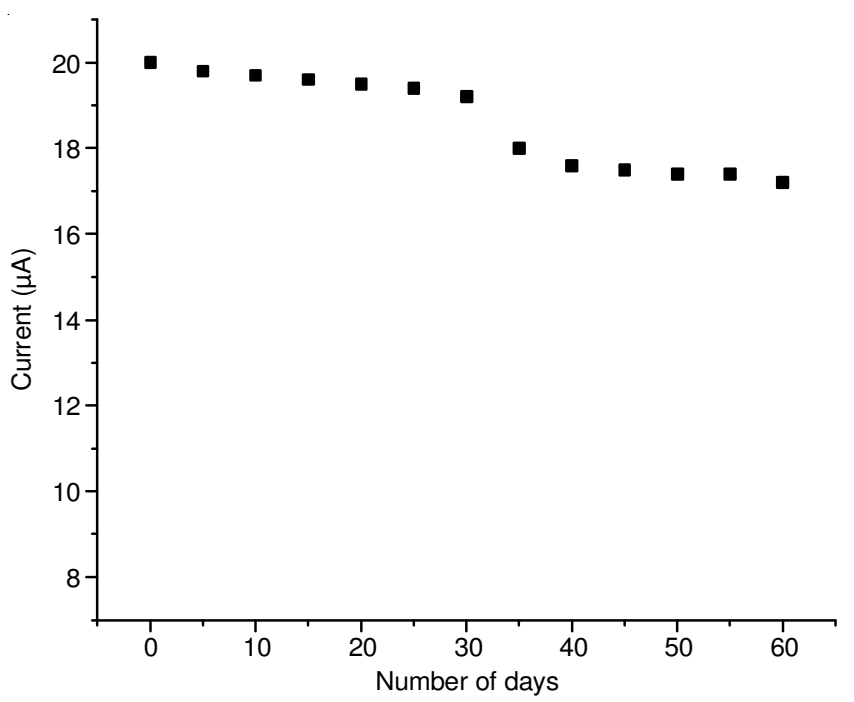

Fig. 5(b). Stability of the Gr/DB30C10/RH electrode storage for 60 days

the creatinase. Attributable to the astounding property of $\mathrm{Gr} /$ DB30C10/RH composite anode, e.g., brilliant conductivity, high available surface zone and great biocompatibility, the arranged biosensor indicated higher affectability, dynamic scope of identification, great manufacture reproducibility, short reaction time and satisfactory strength toward creatinine location. The cost viability and simple strategy for manufacture of Gr/DB30C10/RH biosensor is an extra advantage as contrasted and ordinary anodes. The strategy not exclusively can be utilized to immobilize proteins to build a scope of biosensors additionally might be broad to create other natural particles, for example, immune response and DNA for biosensor.

\section{ACKNOWLEDGEMENTS}

The authors are appreciative to Department of Chemistry and Department of Physics, Savitribai Phule Pune University, India for providing the laboratory facilities.

\section{REFERENCES}

1. N.W. Tietz, Textbook of Clinical Chemistry, Saunders, Philadelphia, edn 1, p. 1810 (1986).

2. F.S. Sena, D. Syed and R.B. McComb, Clin. Chem., 34, 594 (1988)

3. M. Jaffe, Hoppe Seylers Z. Physiol. Chem., 10, 391 (1886).

4. J.A. Weber and A.P. Van Zarten, Clin. Chem., 37, 695 (1991).

5. D. Ammann, W.E. Morf, P. Anker, P.C. Meier, E. Pretsch and W. Simon, Ion-Sel. Electrode Rev., 5, 3 (1983);

https://doi.org/10.1016/B978-0-08-031492-1.50005-X.

6. J.F. Stoddart, Chem. Soc. Rev., 8, 85 (1979); https://doi.org/10.1039/cs9790800085.

7. N.S. Gadhari, B.J. Sanghavi and A.K. Srivastava, Anal. Chim. Acta, 703, 31 (2011); https://doi.org/10.1016/j.aca.2011.07.017

8. S. Upadhyay, G.R. Rao, M.K. Sharma, B.K. Bhattacharya, V.K. Rao and R. Vijayaragha-van, Biosens. Bioelectron., 25, 832 (2009); https://doi.org/10.1016/j.bios.2009.08.036.

9. D. Du, J. Ding, Y. Tao and X. Chen, Sens. Actuators B Chem., 134, 908 (2008);

https://doi.org/10.1016/j.snb.2008.06.040.

10. V.K. Gade, D.J. Shirale, P.D. Gaikwad, P.A. Savale, K.P. Kakde, H.J. Kharat and M.D. Shirsat, React. Funct. Polym., 66, 1420 (2006); https://doi.org/10.1016/j.reactfunctpolym.2006.04.005.

11. D. Lakshmi, P.S. Sharma and B.B. Prasad, Biosens. Bioelectron., 22, 3302 (2007); https://doi.org/10.1016/j.bios.2006.12.011.

12. T. Yao and K. Kotegawa, Anal. Chim. Acta, 462, 283 (2002); https://doi.org/10.1016/S0003-2670(02)00343-4.

13. R. Koncki, I. Walcerz, F. Ruckruh and S. Glab, Anal. Chim. Acta, 333, 215 (1996); https://doi.org/10.1016/0003-2670(96)00266-8.

14. J. Schneider, B. Grundig, R. Renneberg, K. Cammann, M.B. Madaras, R.P. Buck and K.D. Vorlop, Anal. Chim. Acta, 325, 161 (1996); https://doi.org/10.1016/0003-2670(96)00031-1.

15. M.B. Madaras, I.C. Popescu, S. Ufer and R.P. Buck, Anal. Chim. Acta, 319, 335 (1996); https://doi.org/10.1016/0003-2670(95)00508-0. 